\title{
Effects of chronic treatment with a gonadotrophin-releasing hormone agonist on peripheral concentrations of FSH and LH, and ovarian function in heifers
}

\author{
J. G. Gong ${ }^{1,2}$, T. A. Bramley ${ }^{2}$, C. G. Gutierrez ${ }^{1}$, A. R. Peters ${ }^{3}$ and \\ R. $\mathrm{Webb}^{1}$ \\ ${ }^{1}$ Roslin Institute (Edinburgh), Roslin, Midlothian EH25 9PS, UK; ${ }^{2}$ Department of Obstetrics and \\ Gynaecology, University of Edinburgh, Centre for Reproductive Biology, 37 Chalmers Street, Edinburgh \\ EH3 9EW, UK; and ${ }^{3}$ Royal Veterinary College, Potters Bar, Herts EN6 INB, UK
}

\begin{abstract}
The effect of chronic treatment with a gonadotrophin-releasing hormone agonist ( $\mathrm{GnRHa}$ ) on ovarian function in cattle was investigated by injecting heifers i.m. twice a day with saline, $5 \mu \mathrm{g}$ GnRHa (Buserelin) or $10 \mu \mathrm{g} \mathrm{GnRHa}(n=7)$ for 21 days. Blood samples were taken twice a day during the treatment period, and then three times a day for 7 days and once daily for a further 4 days. Frequent samples were also collected on day 1 , day 10 and day 21 of treatment. The ovaries of all heifers were examined daily using real-time ultrasonography throughout the experimental period. No significant differences in the response were observed between two doses of GnRHa. The first GnRHa injection produced a large $\mathrm{LH}$ and FSH surge and this acute response was still present by day 21 of treatment, but both the magnitude and duration of response were significantly attenuated $(P<0.01)$. After an initial increase, LH returned to the basal concentration, which was maintained until the termination of treatment, when concentrations increased significantly, with a preovulatory surge occurring approximately 6 days later. Peripheral FSH concentrations during the oestrous cycle in control animals displayed a pattern of three waves, each of which closely preceded a wave of follicular development. Concentrations of FSH in GnRHa-treated heifers showed a normal pattern for the first wave after the start of treatment. During the next wave, concentrations increased and remained at the peak values until about 4 days after the end of treatment. An additional ovulation was induced in 11 of $14 \mathrm{GnRHa}$-treated heifers within 2-3 days of the start of treatment, and a significant $(P<0.05)$ increase in serum progesterone concentrations was detected 2 days later. All GnRHa-treated heifers then showed a normal follicular wave, with the development and regression of a dominant foilicle. The dominant follicles from the next wave grew to only $7-9 \mathrm{~mm}$ in diameter and remained at this size until the end of treatment, when they resumed growth, ovulated approximately 7 days later and formed corpora lutea. We conclude that chronic treatment of heifers with GnRHa for 3 weeks suppresses pulsatile secretion of LH and blocks the development of dominant follicles beyond $9 \mathrm{~mm}$ in diameter, preventing the preovulatory LH surge and ovulation. However, GnRHa did not suppress the secretion of FSH within the 3 week treatment period. The maintenance of the dominant follicles for an extended period should provide an ideal model to study the control of follicular atresia in cattle in vivo.
\end{abstract}

\section{Introduction}

Ovarian folliculogenesis in cattle is controlled by complex interactions between the classical hypothalamus-pituitaryovarian axis and other intra- and extra-ovarian factors (Ireland, 1987; Fortune et al., 1991; Webb et al., 1992, 1994). While it is generally accepted that gonadotrophins provide the primary

Received 12 June 1995. drive for the growth and development of antral follicles (Greep et al., 1942; McNeilly et al., 1991, 1992; Scaramuzzi et al., 1993; Campbell $e$ al., 1995), the relative importance of FSH and LH at different stages of follicle development is still poorly understood, especially in cattle. The task of unravelling these mechanisms has been complicated by findings that numerous non-gonadotrophin factors are involved in the control of folliculogenesis in an endocrine, paracrine or autocrine manner (Lobb and Dorrington, 1992; Webb et al., 1994; Campbell et al., 
1995; Monget and Monniaux, 1995). During folliculogenesis in mammals, most follicles undergo atresia. While it has been proposed that this is a process of programmed cell death (apoptosis, Hsueh et al., 1994), little is understood of the control mechanisms.

Studies in sheep have demonstrated that the early stages of antral follicle development are not dependent on gonadotrophin support, as antral follicles up to approximately $2 \mathrm{~mm}$ in diameter are still present after hypophysectomy (Dufour et al., 1979; Driancourt et al., 1987), hypothalamic-pituitary stalk disconnection (Sawyer et al., 1991; Eckery et al., 1993), and suppression of gonadotrophin secretion by immunoneutralization of LH-releasing hormone, chronic treatment with gonadotrophin-releasing hormone $(\mathrm{GnRH})$ agonist or acute treatment with GnRH antagonist (McNeilly et al., 1991, 1992; Campbell ef al., 1995). Experimental models have been developed in sheep using GnRH agonists or antagonists to study the physiological roles of FSH and $\mathrm{LH}$ in the further development of gonadotrophin-independent follicles (Picton et al., 1990; McNeilly et al., 1991, 1992; Campbell et al., 1995).

Since factors other than gonadotrophins can have a profound effect on the development of small antral follicles (Gong, 1992; Webb et al., 1994), there may be a similar gonadotrophin-independent stage of follicle development in cattle. However, this has yet to be proven experimentally. Therefore, the objectives of this study were: (1) to determine whether chronic treatment of heifers with a GnRH agonist ( $\mathrm{GnRHa}$ ) can suppress the secretion of FSH and LH and inhibit the development of ovarian follicles; and (2) to investigate whether GnRHa treatment can be used to develop an experimental model to study the control of ovarian follicular development and atresia in cattle. Such a model in cattle would offer an advantage over those in sheep in that ovarian follicle growth dynamics can be easily monitored by real-time ultrasonography (Boland et al., 1990; Gong et al., 1993).

\section{Materials and Methods}

\section{Experimental animals}

The animals used for this study were Hereford cross Friesian beef heifers, 2-3 years of age. The heifers were kept indoors under a natural photoperiod in a large court, fed hay and concentrates twice a day with water provided ad libitum. Before the experiment, animals were given halter training and checked for oestrous cyclicity. Oestrus was monitored by behavioural observation four times a day (until all animals showed oestrus after the second Estrumate injection and after the termination of GnRHa treatment, or from day 19 to 23 after synchronized oestrus in the controls), aided by a Kamar heatmount detector (Kamar Inc., Steamboat Springs, CO).

\section{Experimental procedures}

The oestrous cycles of 21 heifers were synchronized by two i.m. injections of $500 \mu \mathrm{g}$ synthetic PGF2 $\alpha$ analogue (Estrumate: Coopers Animal Health Ltd, Crewe), given 11 days apart. All heifers ovulated 3-4 days after the second injection, and then a follicular wave emerged. Animals were assigned to three treatment groups in a randomized block design: I, control; II, $\mathrm{GnRHa}(5 \mu \mathrm{g})$; and III, GnRHa (10 $\mu \mathrm{g})$. Starting from day 5 of the synchronized oestrous cycle (day of oestrus was taken as day 0), heifers in Groups II and III were injected i.m. twice a day (09:00 and 21:00 h) with a GnRHa (Buserelin: Hoechst Animal Health, Hounslow) for 21 days, while control animals received saline. Blood samples were taken by jugular venepuncture from all animals twice a day just before each injection from day 3 of the synchronized oestrous cycle until the end of GnRHa treatment, and then three times a day (07:00, 15:00 and 23:00 h) for 7 days to monitor recovery in pituitary function, and once a day $(09: 00 \mathrm{~h})$ for a further 4 days to assess corpus luteum function. Serum was harvested and stored at $-20^{\circ} \mathrm{C}$ until assayed for progesterone, FSH and LH concentrations by specific radioimmunoassays. Serial blood samples were collected, via jugular cannula, on day 1 , day 10 (every $15 \mathrm{~min}$ for $8 \mathrm{~h}$ ) and day 21 (every hour for $7 \mathrm{~h}$ ) of GnRHa treatment. Plasma was stored frozen for the subsequent measurement of FSH and LH concentrations by radioimmunoassay. The ovaries of all heifers were scanned daily throughout the experimental period using real-time ultrasonography to monitor the dynamics of follicle growth and development (Gong et al., 1993).

\section{Hormone assays}

Progesterone. Serum progesterone concentrations were measured using a radioimmunoassay described by Corrie $e t$ al. (1981), as modified by Law et al. (1992). The minimum detectable concentrations, as calculated by assay analysis programme AssayZap, were $0.13 \mathrm{ng} \mathrm{ml}^{-1}$. All the samples were analysed in a single assay with an intra-assay coefficient of variation $(\mathrm{CV})$ of $5.9 \%$.

$L H$. Peripheral concentrations of $L H$ were determined by a double-antibody radioimmunoassay used routinely in our laboratory (Price et al., 1987). The LH standard used was a USDA reference preparation (USDA-bLH-B5). The sensitivity of the assay was $0.12 \mathrm{ng} \mathrm{ml}^{-1}$. The inter- and intra-assay CVs, calculated from six bovine quality control samples (two low, two medium and two high in relation to the standard curve) in each of six separate assays, were $7.6 \%$ and $5.7 \%$, respectively.

FSH. Peripheral FSH concentrations were measured using a radioimmunoassay developed and validated from the ovine FSH assay protocol described by McNeilly et al. (1988). The assay used a rabbit anti-ovine FSH serum (NIDDK-anti-oFSHI), a pure bovine FSH preparation (USDA-bFSH-I2) as the standard, and ${ }^{125}$ I-labelled ovine FSH (NIDDK-oFSH-II) as tracer. The standard curve ranged from 10 to $5000 \mathrm{pg}$ per tube and antiserum was used at a final dilution of 1:120 000. Serum samples from both intact and ovariectomized heifers produced displacement curves parallel to the standard curve. The detection limit of the assay was $0.11 \mathrm{ng} \mathrm{ml}^{-1}$. The inter- and intra-assay $\mathrm{CVs}$, calculated from six bovine quality control samples (two low, two medium and two high in relation to the standard curve) in each of eight separate assays, were $8.4 \%$ and $6.1 \%$, respectively. Crossreaction with pure bovine LH (USDAbLH-I2) was minimal $(<0.01 \%)$; this was verified by the 

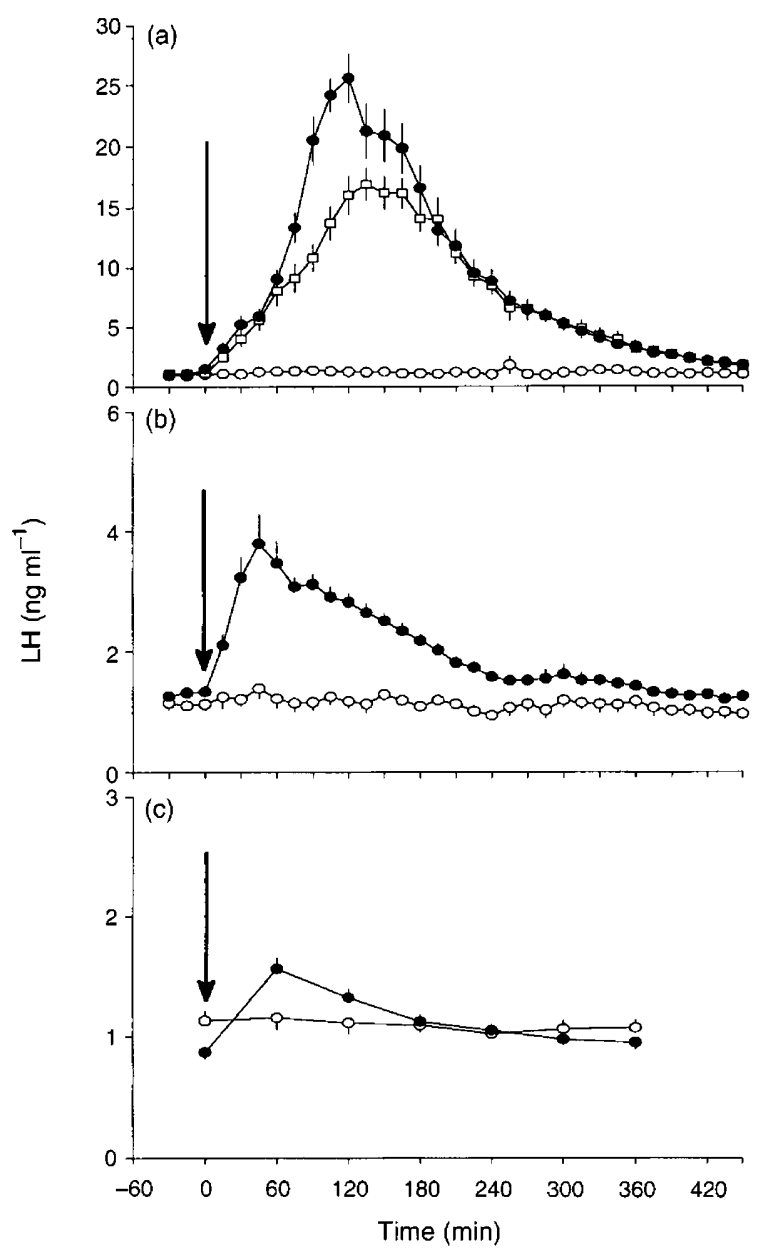

Fig. 1. Mean ( \pm SEM) plasma LH concentrations before and after an i.m. injection of GnRHa (arrow). (a) Day I of chronic GnRHa treatment: (O), control, $n=7 ;(\square)$, GnRHa $5 \mu \mathrm{g}, n=7$; (O), GnRHa $10 \mu \mathrm{g}, n=7$. (b) Day 10: (O), control, $n=7$; (O), GnRHa pooled, $n=14$. (c) Day 21: (O), control, $n=7$; (O), GnRHa pooled, $n=14$. Blood samples were collected every $15 \mathrm{~min}$ for $8 \mathrm{~h}$ on days 1 and 10 , and every hour for $7 \mathrm{~h}$ on day 21 . Note the different scales in the $\mathrm{y}$ axes between different panels.

observation that a single i.v. infusion of $5 \mu \mathrm{g} \mathrm{LH}$ into heifers produced a uniform increase in plasma LH concentrations, whereas no changes were detected in peripheral FSH concentrations (data not shown). Furthermore, growth hormone, prolactin and thyroid-stimulating hormone did not crossreact with the antiserum (data not shown).

\section{Statistical analyses}

All the data are presented as means \pm SEM unless otherwise specified. All the data, except the acute response of $\mathrm{LH}$ to GnRHa injection on day I of treatment (see Fig. 1a), from two GnRHa-treated groups were pooled for presentation and statistical analyses, as no significant difference was observed between the groups. Statistical differences in peripheral hormone concentrations between groups were analysed by analysis of variance (ANOVA) allowing for repeated measurements.

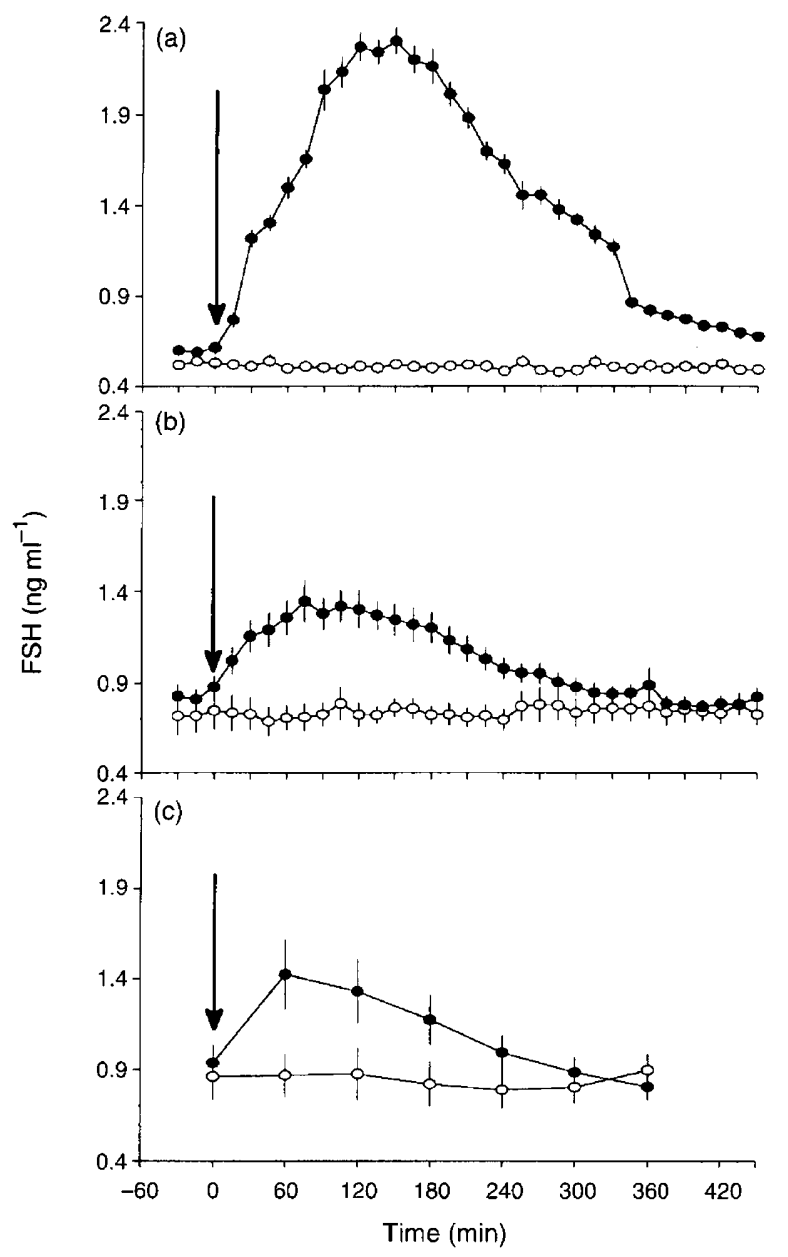

Fig. 2. Mean ( \pm SEM) plasma FSH concentrations before and after an i.m. injection of GnRHa on (a) day 1, (b) day 10 and (c) day 21 of chronic treatment with GnRHa. Blood samples were collected every $15 \mathrm{~min}$ for $8 \mathrm{~h}$ on days $\mathrm{I}$ and 10 , and every hour for $7 \mathrm{~h}$ on day 21 . (O), control, $n=7$; $(\bigcirc)$, GnRHa pooled, $n=14$. The time of GnRHa or saline injections is indicated by the arrows.

Data obtained from ultrasonography were analysed as described by Gong et al. (1993). All statistical analyses were performed on an Apple Macintosh computer using Minitab software (Pennsylvania State University).

\section{Results}

\section{Acute response of $F S H$ and $L H$ to $G n R H a$ injection}

Plasma concentrations of both LH and FSH increased $(P<0.01)$ within $15 \mathrm{~min}$ after the first GnRHa injection, reaching preovulatory surge-like concentrations approximately $2 \mathrm{~h}$ later (Figs $1 \mathrm{a}$ and 2a). Both FSH and LH concentrations were still high at the end of the sampling period ( $7.5 \mathrm{~h}$ after GnRHa injection). The acute response of LH and FSH to GnRHa injection was still present 10 and 21 days after the start of treatment (Figs 1b, c and 2b, c), but the magnitude of response was significantly reduced $(P<0.01)$ 


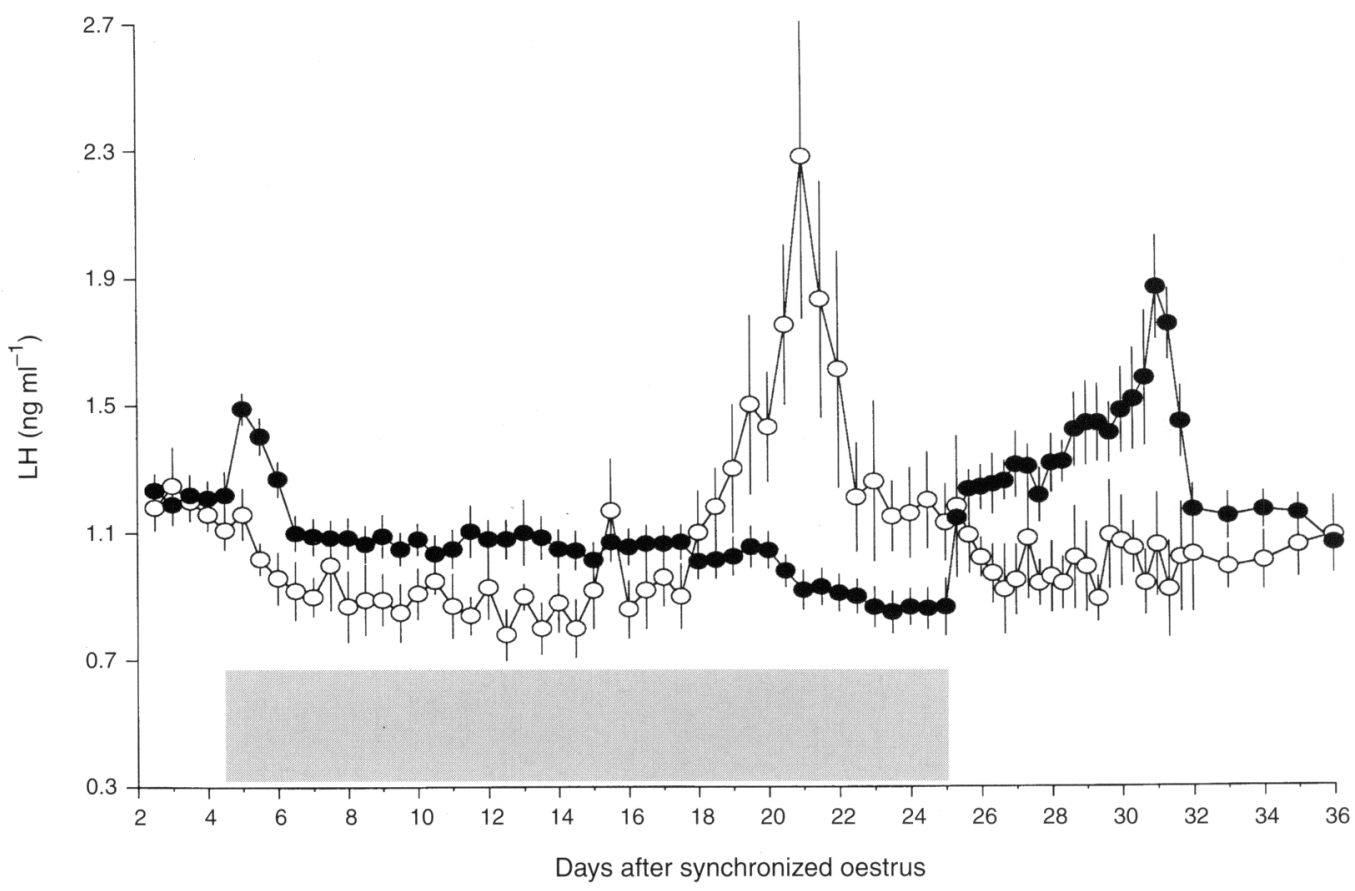

Fig. 3. Mean ( \pm SEM) serum LH concentrations for control $(O, n=7)$ and GnRHa-treated $(\boldsymbol{O}, n=14)$ groups throughout the experimental period. Heifers were injected i.m. twice a day (09:00, 21:00 h) with GnRHa or saline for 21 days, as indicated by shaded area. Blood samples were collected twice a day (09:00, 21:00 h) before and during the treatment period, three times a day $(07: 00,15: 00,23: 00 \mathrm{~h})$ for a further 7 days and then once a day (09:00 h) for 4 days.

with duration of treatment. While FSH and LH concentrations were still high at the end of the sampling period on day 10 of treatment, the increase lasted only for $2-3 \mathrm{~h}$ on day 21 of treatment.

\section{Peripheral $\mathrm{LH}$ concentrations throughout the experimental period}

Peripheral LH concentrations in the control heifers remained low throughout the experimental period, except when a preovulatory surge was detected 20-21 days after the synchronized oestrus. Concentrations of $\mathrm{LH}$ increased significantly $(P<0.01)$ after GnRHa treatment, and then fell by day 3 of treatment to constant basal values which were significantly higher $(P<0.05)$ than those of control animals (Fig. 3). This basal value of LH decreased further by day 16-17 of treatment, and no preovulatory surge was observed. After GnRHa treatment had ceased, serum LH concentrations increased $(P<0.01)$ immediately and a preovulatory surge was detected 6-7 days later.

\section{Peripheral FSH concentrations throughout the experimental period}

Serum concentrations of FSH in the control animals displayed a three-wave pattern during the oestrous cycle (Fig. 4). After an initial significant $(P<0.01)$ increase for 2 days after the start of treatment, peripheral FSH concentrations in the GnRHa-treated heifers returned to basal values before showing a normal wave as seen in the controls. During the next wave, FSH increased and remained at concentrations similar to the peak values of the FSH waves seen in control heifers until 4-5 days after the termination of GnRHa treatment. FSH then declined to basal concentrations before showing another increase.

\section{Serum progesterone concentrations throughout the experimental period}

Progesterone concentrations during the experiment in the control heifers displayed follicular and luteal phase patterns characteristic of the normal oestrous cycle (Fig. 5). In the GnRHa-treated group, progesterone began to increase $24 \mathrm{~h}$ after the start of GnRHa treatment, but only became significantly $(P<0.05)$ higher than the control group 5 days later. Progesterone concentrations in both groups began to decline precipitously on day 17 of the oestrous cycle, reaching the assay detection limit 4 days later. Progesterone in control animals increased normally during the next oestrous cycle, but concentrations in GnRHa-treated heifers remained at the assay detection limit until 10 days after the termination of GnRHa treatment, and then increased coincident with the formation of a new corpus luteum.

\section{Ovarian activity and follicular dynamics}

GnRHa treatment induced dominant follicles to ovulate in 11 of 14 (5 of 7 in the group treated with $5 \mu \mathrm{g} \mathrm{GnRHa}$ and 6 of 7 in the group treated with $10 \mu \mathrm{g}$ ) heifers within 2-3 days of the start of treatment. Induced corpora lutea were clearly detected by ultrasound $4-5$ days after the start of GnRHa 


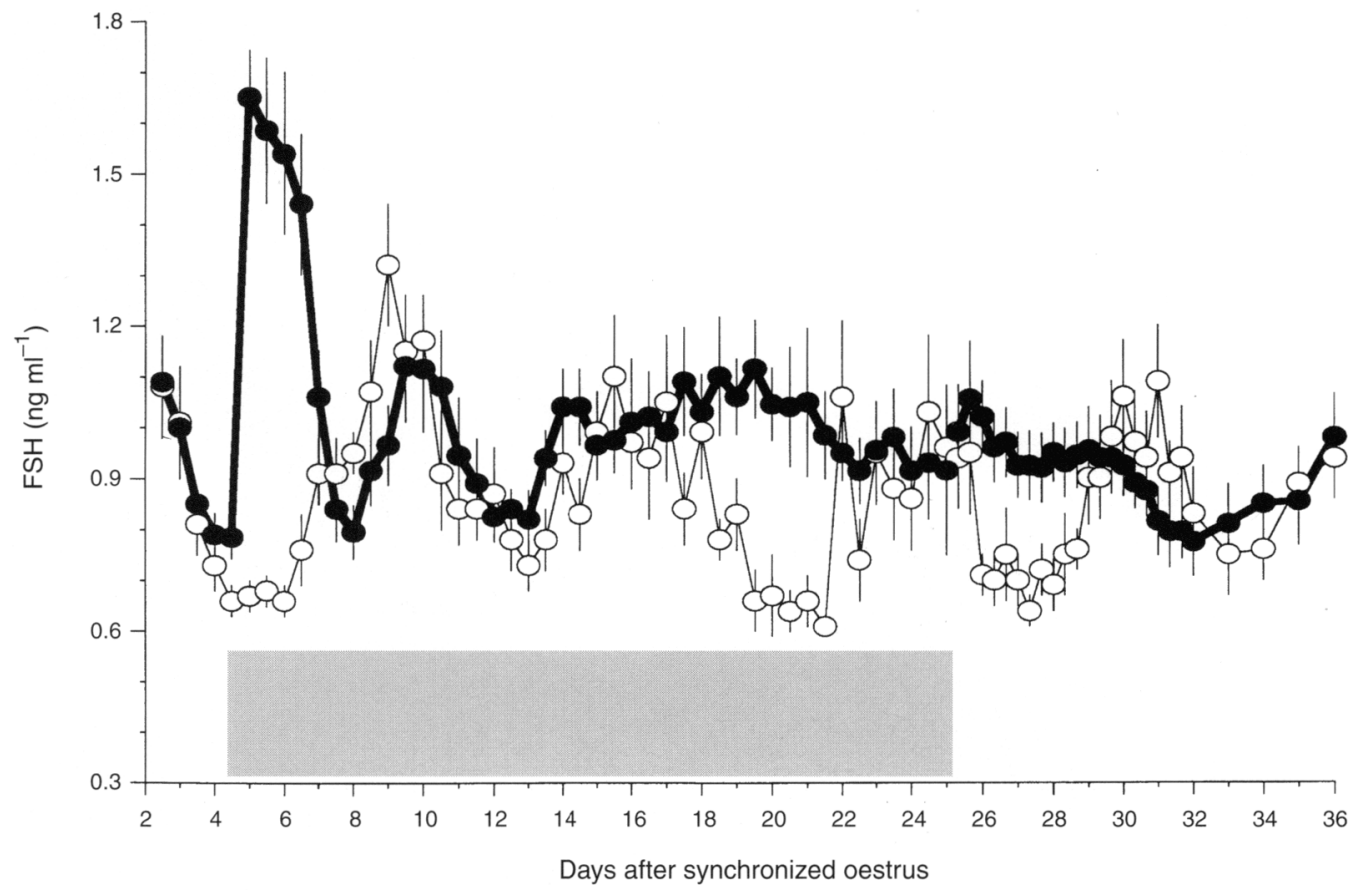

Fig. 4. Mean $( \pm$ SEM) serum FSH concentrations for control $(O, n=7)$ and GnRHa-treated $(\bullet, n=14)$ groups throughout the experimental period. Heifers were injected i.m. twice a day (09:00, 21:00 h) with GnRHa or saline for 21 days, as indicated by shaded area. Blood samples were collected twice a day (09:00, 21:00 h) before and during the treatment period, three times a day $(07: 00,15: 00,23: 00 \mathrm{~h})$ for a further 7 days and then once a day $(09: 00 \mathrm{~h})$ for 4 days

treatment. Both induced and endogenous corpora lutea in GnRHa-treated heifers regressed at the same time as corpora lutea in control animals. Control animals displayed oestrus 19-21 days after the synchronized oestrus, and then ovulation and formation of corpora lutea occurred. In contrast, oestrus was not observed in GnRHa-treated heifers until 31-33 days after the synchronized oestrus. Ovulations then occurred and corpora lutea were detected by ultrasound 3 days later.

Six heifers in the control group displayed three waves of follicular development during the oestrous cycle, while the remaining heifer had a two-wave pattern. Each follicular wave was closely preceded by an increase in peripheral FSH concentrations (data not shown). After the start of GnRHa treatment, all animals (with or without an induced ovulation) showed a normal follicular wave with the development of a dominant follicle (Fig. 6). This dominant follicle then regressed and was followed by growth of a new wave of follicles. However, the dominant follicles from this new wave grew to only $7-9 \mathrm{~mm}$ in diameter and remained at this size until the end of the GnRHa treatment. After the termination of treatment, these dominant follicles resumed growth immediately, reached ovulatory size within 4 days and ovulated a further 3 days later. Ovulations were confirmed by the subsequent detection of a corpus luteum by ultrasonography.

\section{Discussion}

This study has demonstrated that treatment of heifers with GnRHa twice a day for 3 weeks significantly altered the secretion of FSH and LH. The treatment suppressed the development of dominant follicles, and blocked the preovulatory LH surge and ovulation.

The patterns of peripheral FSH and LH concentrations and ovarian follicular dynamics in control heifers throughout the oestrous cycles in this study were similar to those reported by Boland et al. (1990), Adams et al. (1992), Webb et al. (1992) and Gong et al. (1993). The observation that serum FSH concentrations displayed a wave pattern and that each FSH wave was closely associated with a wave of follicular development (Adams et al., 1992) was confirmed. In addition, as reported by Gong et al. (1993), most animals had a three-wave pattern of follicular development during the oestrous cycle.

The first GnRHa injection induced a preovulatory surge-like $\mathrm{LH}$ release in all animals. Similar results were reported in both sheep and cattle (repeated injections: Dobson, 1985; McLeod et al., 1985; Peters et al., 1985; continuous infusion: D’Occhio et al., 1989; McLeod et al., 1991; Grasselli et al., 1993; Ronayne et al., 1993). An acute response of FSH release to GnRHa administration was also observed in this study. The acute response of FSH and LH to GnRHa was still present after 21 days of treatment, suggesting that the treatment did not completely suppress the synthesis, or exhaust the storage, of FSH and LH, in support of the results of Lamming and McLeod (1988; continuous infusion). This was further supported by the observation that circulating $\mathrm{LH}$ concentrations increased significantly immediately after the termination of $\mathrm{GnRHa}$ treatment, and reached the preovulatory surge approximately 6 days later. 


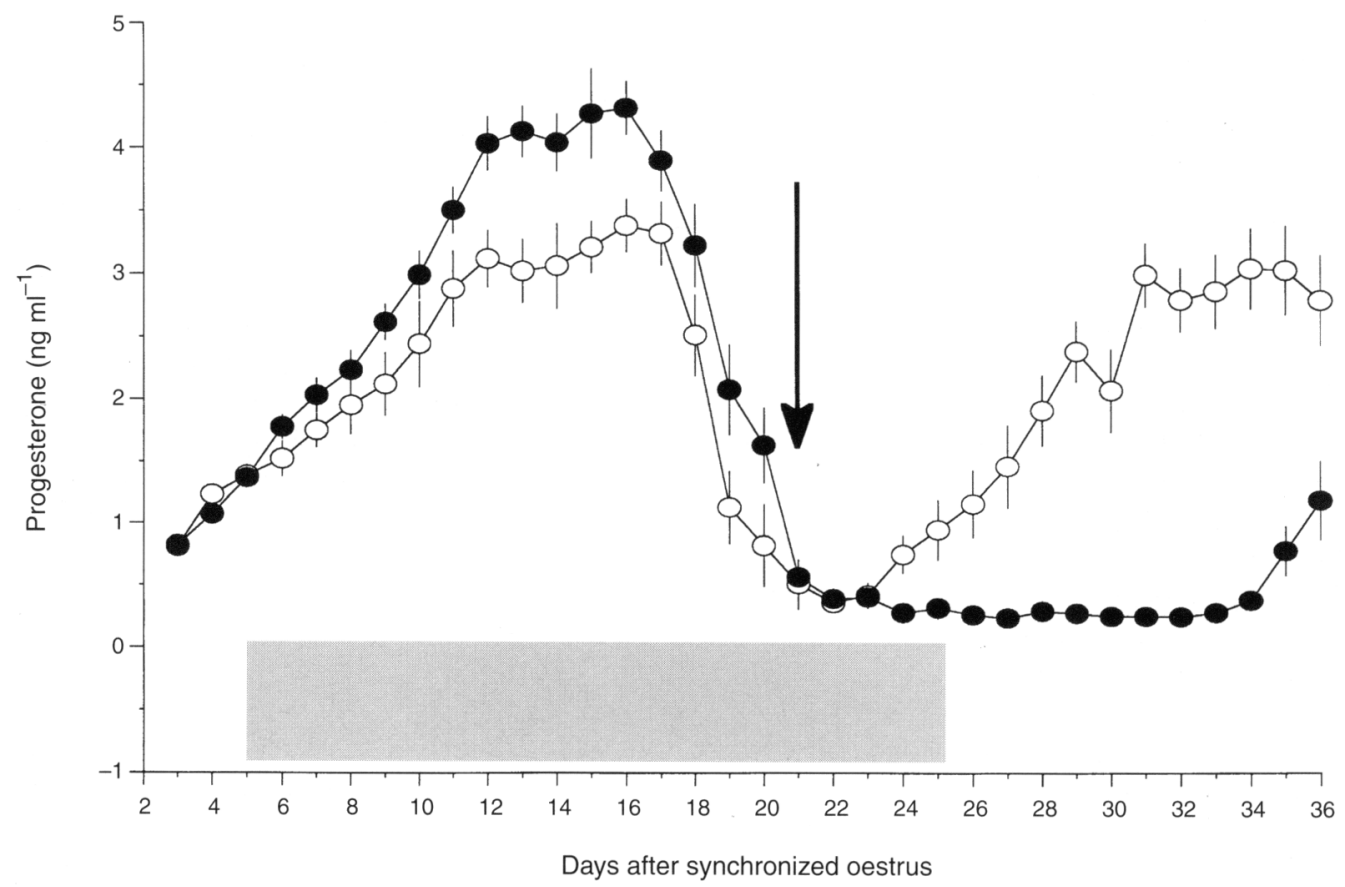

Fig. 5. Mean ( \pm SEM) daily serum progesterone concentrations for control $(O, n=7)$ and GnRHa-treated ( $n=14)$ groups throughout the experimental period. Heifers were injected i.m. twice a day (09:00, 21:00 h) with GnRHa or saline for 21 days, as indicated by shaded area. The time when control heifers displayed oestrus during the experiment is indicated by the arrow.

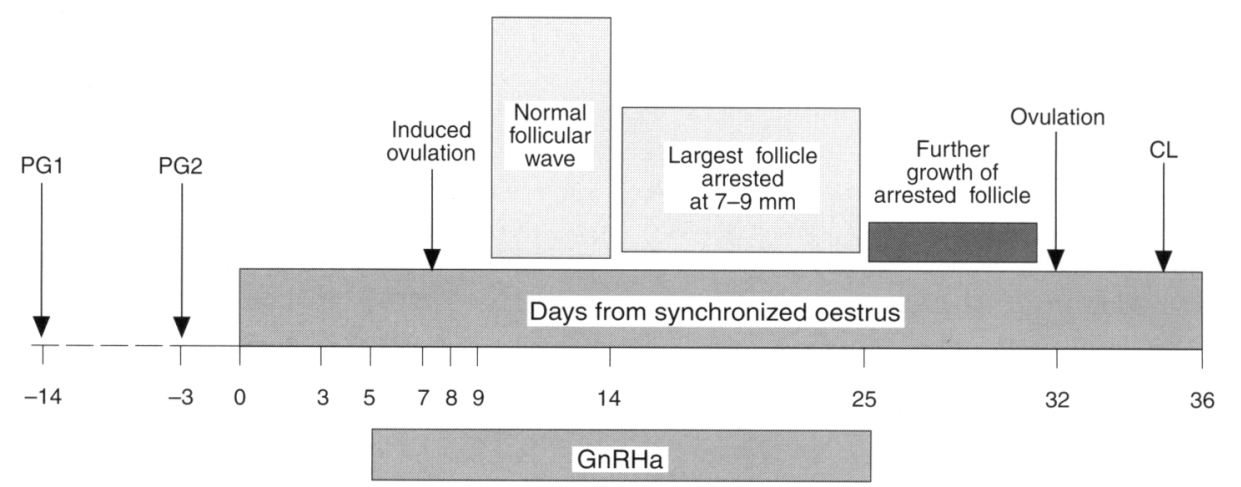

Fig. 6. Schematic summary of ovarian follicular dynamics for GnRHa-treated heifers $(n=14)$ throughout the experimental period. Animals were injected i.m. twice a day with GnRHa for 21 days, as indicated, and ovaries were scanned daily using real-time ultrasonography throughout the experiment. CL: corpus luteum.

One of our initial intentions for carrying out serial blood samplings at different stages of GnRHa treatment was to examine the effect of treatment on $\mathrm{LH}$ pulsatile secretion. While well-defined LH pulses were detected in the control heifers, LH pulses could not be evaluated in GnRHa-treated animals because of the acute $\mathrm{LH}$ response to each GnRHa injection. Studies in both sheep (McNeilly and Fraser, 1987) and cattle (D'Occhio ef al., 1989; Grasselli et al., 1993; Ronayne et al, 1993) showed that chronic treatment with GnRHa decreases or abolishes the pulsatile secretion of LH. Our data support these results, as mean serum LH concentrations (Fig. 3) were constant (with small standard error) during the period from day 3 to the end of treatment, suggesting a non-pulsatile mechanism of LH secretion. In addition, in agreement with previous studies (McNeilly and Fraser, 1987; D'Occhio et al., 1989; McLeod et al., 1991), GnRHa treatment did not suppress basal peripheral LH concentrations in our study. In fact, basal LH concentrations in GnRHa-treated animals were significantly higher than in the controls up to approximately day 16 of treatment, and then returned to concentrations similar to those in the mid-luteal phase of control heifers.

In the study reported here, GnRHa treatment first increased circulating concentrations of FSH and then disrupted the normal wave pattern of FSH secretion. This is in agreement with Peters et al. (1985), but in contrast with reports by McLeod et al. (1985) and D'Occhio et al. (1989), who found no 
effect of GnRHa treatment on peripheral FSH concentrations in prepubertal heifers and postpartum acyclic cows, respectively, and the results of McNeilly and Fraser (1987) who demonstrated a suppression of plasma FSH concentrations by GnRHa in ewes. The reason for these differences is unclear, although they may be due to differences in the physiological status of animals as well as in species.

The LH surge provoked by GnRHa injection on day 5 of the oestrous cycle induced the dominant follicles to ovulate in 11 of 14 heifers. This is in agreement with studies that have shown that an additional corpus luteum could be induced in $75-80 \%$ of animals by treating heifers with a single dose of synthetic GnRHa on day 6 of the oestrous cycle (Rusbridge, 1993). In addition, when a single dose of LH (in the form of hCG) was given on day 4-7 of the oestrous cycle, ovulation could be induced in approximately $80 \%$ of heifers (Price and Webb, 1989). However, it is not clear why only $80 \%$ of animals ovulated, even though all the treated heifers had an induced LH surge and a dominant follicle present in the ovary. Possibly the response is related to the stage of differentiation of the dominant follicle, since about $80 \%$ of heifers used in this study had a three-wave pattern of follicular development per oestrous cycle, while the remainder had two waves (Gong et al., 1993).

After the start of treatment, peripheral concentrations of progesterone in GnRHa-treated heifers were higher than in the controls throughout the rest of the luteal phase. Presumably, the initial nonsignificant increase in serum progesterone concentrations represented the stimulatory effect of increased LH acting on the endogenous corpora lutea (Baird, 1992; Rajamahendran and Sianangama, 1992; Mann et al., 1995), whereas the significant increase 5 days later was a result of this effect in addition to progesterone secretion by the induced corpora lutea (Rusbridge, 1993). Indeed, serum progesterone concentrations in the three heifers without induced corpora lutea was not significantly higher than those in control animals. This stimulatory effect of LH on the corpus luteum has been associated with increased pregnancy rates observed after treatment of cattle with GnRH or hCG during the mid-luteal phase after artificial insemination (Drost and Thatcher, 1992; Rajamahendran and Sianangama, 1992; Drew and Peters, 1994; Mann et al., 1995). However, as reported by Rusbridge (1993), both endogenous and induced corpora lutea in GnRHatreated animals regressed at the same time as in control heifers, even though basal LH concentrations were still high (Fig. 3).

After induced ovulation or regression of the first crop of dominant follicles, a normal wave of follicular development occurred, preceded by an increase in peripheral FSH concentrations (Turzillo and Fortune, 1990; Adams et al., 1992). The dominant follicles from the next wave grew to $7-9 \mathrm{~mm}$ in diameter, but their further growth was then arrested. The mechanism for this is not yet clear, but it is likely that these dominant follicles did not receive adequate $\mathrm{LH}$ pulse support to undergo further development. This is supported by findings that only bovine granulosa cells of follicles $\geq 9 \mathrm{~mm}$ in diameter express mRNA encoding the LH receptor ( $X_{\mathrm{u}}$ et al., 1995). Conversely, it has been shown that the lifespan of dominant follicles in cattle can be extended with adequate LH pulse stimulation (Fortune et al., 1991; Savio et al., 1993).
After the arrest of dominant follicle growth, peripheral FSH remained at high concentrations, presumably because of a lack of negative feedback by oestradiol or inhibin secreted by large dominant follicles (Webb et al., 1992; Campbell et al., 1995). It is significant that these growth-arrested follicles could be maintained for an extended period without regression occurring and that these follicles could resume growth and develop to ovulation in response to increased serum LH concentrations, but in the absence of a significant change in FSH concentrations, after the termination of GnRHa treatment. The normal development of these arrested follicles was demonstrated by the induction of a decrease in serum FSH concentrations, a preovulatory LH surge and oestrous behaviour, and the subsequent ovulation and formation of a functional corpus luteum.

In agreement with D'Occhio et al. (1989) and McLeod et al. (1991), repeated treatment with GnRHa blocked the preovulatory LH surge and ovulation. This was presumably a result of the downregulatory effects of $\mathrm{GnRHa}$ on the pituitary gonadotrophs, although it could also have been due to the lack of the final maturation of the dominant follicles, which would secrete the large amounts of oestradiol necessary to induce the preovulatory LH surge (Karsch et al., 1992).

GnRHa treatment in this study did not suppress FSH secretion, in contrast to the study in sheep by McNeilly and Fraser (1987). Therefore, the presence or otherwise of a gonadotrophin-independent stage of follicular development in cattle, like that in sheep, remains to be established. These differences may be due to the treatment protocols used (twice daily i.m. injection for 3 weeks) compared with s.c. implanted osmotic minipumps which release GnRHa constantly (McNeilly and Fraser, 1987). However, recent data (Gong et al., 1995) suggest that these differences are more likely to reflect a species difference, and that a longer treatment period is required in cattle to downregulate the pituitary gonadotrophs completely. These aspects are being investigated further to develop an experimental model in cattle similar to that in sheep (McNeilly et al., 1991, 1992).

In conclusion, chronic treatment of heifers with a GnRHa for 3 weeks suppressed the pulsatile secretion of $\mathrm{LH}$ and the development of dominant follicles beyond $9 \mathrm{~mm}$ in diameter, and blocked the preovulatory LH surge and ovulation. The maintenance of the dominant follicles for an extended period should provide an ideal model to study the control of follicular atresia in cattle in vivo. However, GnRHa did not suppress the secretion of FSH within the 3 week treatment period. We were therefore unable to demonstrate a gonadotrophin-independent stage of follicular development in this study. The experimental protocol will require modification to develop a model in cattle like that in sheep.

This work was supported by BBSRC, MAFF and OST. The authors thank NIDDK, NHPP, USDA Animal Hormone Program and SAPU for the reagents for radioimmunoassays; Hoechst UK for the gift of Buserelin; I. Swanston (MRC Reproductive Biology Unit) for progesterone tracer and R. Staigmiller (USDA) for bLH antiserum. The authors also thank the staff at the institute's LAU and Dryden farm for the care and handling of experimental animals, G. Baxter for technical assistance and A. S. McNeilly (MRC Reproductive Biology Unit) for helpful discussions. 


\section{References}

Adams GP, Matteri RL, Kastelic JP, Ko JCH and Ginther OJ (1992) Association between surges of follicle-stimulating hormone and the emergence of follicular waves in heifers Journal of Reproduction and Fertility 94 177-188

Baird DT (1992) Luteotrophic control of the corpus luteum Animal Reproduction Science 28 95-102

Boland MP, Murphy MG and Roche JF (1990) The use of ultrasound to monitor ovarian function in farm animals AgBiotech News and Information 2 841-844

Campbell BK, Scaramuzzi RJ and Webb R (1995) Control of antral follicle development and selection in sheep and cattle journal of Reproduction and Fertility Supplement $49335-350$

Corrie JET, Hunter WM and Macpherson IS (1981) A strategy for radioimmunoassay of plasma progesterone with the use of a homologous site ${ }^{125}$ I-labelled radioligand Clinical Chemistry 27 594-599

D'Occhio MJ, Gifford DR, Earl CR, Weatherly T and von Rechenberg W (1989) Pituitary and ovarian responses of post-partum acyclic beef cows to continuous long-term GnRH and GnRH agonist treatment Journal of Reproduction and Fertility 85 495-502

Dobson $\mathrm{H}$ (1985) Effects of chronic treatment with a $\mathrm{GnRH}$ agonist on oestrous behaviour and on the secretion of $\mathrm{LH}$ and progesterone in the ewe Theriogenology 24 I-II

Drew SB and Peters AR (1994) Effect of buserelin on pregnancy rates in dairy cows The Veterinary Record 134 267-269

Driancourt MA, Fry RC, Clarke IJ and Cahill LP (1987) Follicular growth and regression during the 8 days after hypophysectomy in sheep Journal of Reproduction and Fertility $79635-641$

Drost M and Thatcher WW (1992) Application of gonadotrophin releasing hormone as therapeutic agent in animal reproduction Animal Reproduction Science 28 11-19

Dufour J, Cahill LP and Mauleon P (1979) Short- and long-term effects of hypophysectomy and unilateral ovariectomy on ovarian follicular populations in sheep Journal of Reproduction and Fertility 57 301-309

Eckery DC, Moeller CL, Nett TM and Sawyer HR (1993) Recombinant bovine somatotropin (rbST, Sometribove) maintains the sensitivity of ovarian follicles to gonadotropins in hypophysectomized ewes Biology of Reproduction 48 Abstract 337

Fortune JE, Sirois J, Turzillo AM and Lavoir M (1991) Follicle selection in domestic species Journal of Reproduction and Fertility Supplement 43 187-198

Gong JG (1992) The Role of Growth Hormone, Insulin-like Growth Factor I and Insulin in the Control of Ovarian Follicular Growth and Development in the Heifer PhD Thesis, The University of Edinburgh

Gong JG, Bramley TA and Webb R (1993) The effect of recombinant bovine somatotrophin on ovarian follicular growth and development in heifers Journal of Reproduction and Fertility 97 247-254

Gong JG, Campbell BK, Bramley TA, Peters AR and Webb R (1995) Evolution of the requirement for FSH and $\mathrm{LH}$ during ovarian follicle growth and development in cattle Journal of Reproduction and Fertility Abstract Series 15 Abstract 13

Grasselli F, Baratta M and Tamanini C (1993) Effects of a GnRH analogue (buserelin) infused via osmotic minipumps on pituitary and ovarian activity of prepubertal heifers Animal Reproduction Science 32 153-161

Greep RO, van Dyke HB and Chow BF (1942) Gonadotropins of the swine pituitary Endocrinology 30 635-649

Hsueh AJW, Billig H and Tsafriri A (1994) Ovarian follicle atresia: a hormonally controlled apoptotic process Endocrine Reviews 15 707-724

Ireland JJ (1987) Control of follicular growth and development Journal of Reproduction and Fertility Supplement 34 39-54

Karsch FJ, Moenter SM and Caraty A (1992) The neuroendocrine signal for ovulation Animal Reproduction Science 28 329-341

Lamming GE and McLeod BJ (1988) Continuous infusion of GnRH reduces the LH response to an intravenous $\mathrm{GnRH}$ injection but does not inhibit endogenous LH secretion in cows journal of Reproduction and Fertility $\mathbf{8 2}$ $237-246$

Law AS, Baxter G, Logue DN, O'Shea T and Webb R (1992) Evidence for the action of bovine follicular fluid factor(s) other than inhibin in suppressing follicular development and delaying oestrus in heifers Journal of Reproduction and Fertility 96 603-616

Lobb DK and Dorrington J (1992) Intraovarian regulation of follicular development Animal Reproduction Science 28 343-354
McLeod BJ, Peters AR, Haresign W and Lamming GE (1985) Plasma LH and FSH responses and ovarian activity in prepubertal heifers treated with repeated injections of low doses of GnRH for $72 \mathrm{~h}$ Journal of Reproduction and Fertility 74 589-596

McLeod BJ, Dodson SE, Peters AR and Lamming GE (1991) Effects of a GnRH agonist (Buserelin) on LH secretion in post-partum beef cows Animal Reproduction Science 24 1-11

McNeilly AS and Fraser HM (1987) Effect of gonadotrophin-releasing hormone agonist-induced suppression of LH and FSH on follicle growth and corpus luteum function in the ewe Journal of Endocrinology 115 273-282

McNeilly AS, Picton HM, Campbell BK and Baird DT (1991) Gonadotrophic control of follicle growth in the ewe Journal of Reproduction and Fertility Supplement 43 177-186

McNeilly AS, Crow W, Brooks J and Evans G (1992) Luteinizing hormone pulses, follicle-stimulating hormone and control of follicle selection in sheep Journal of Reproduction and Fertility Supplement 45 5-19

McNeilly JR, Fordyce M, Land R, Martin GB, Springbett AJ and Webb R (1988) Changes in the feedback control of gonadotrophin secretion in ewes from lines selected for testis size in the ram lamb Journal of Reproduction and Fertility $84 \quad 213-221$

Mann GE, Lamming GE and Fray MD (1995) Plasma oestradiol and progesterone during early pregnancy and the effects of treatment with buserelin Animal Reproduction Science 37 121-131

Monget P and Monniaux D (1995) Growth factors and the control of folliculogenesis Journal of Reproduction and Fertility Supplement 49 321-333

Peters AR, Pimentel MG and Lamming GE (1985) Hormone responses to exogenous GnRH pulses in post-partum dairy cows Journal of Reproduction and Fertility 75 557-565

Picton HM, Tsonis CG and McNeilly AS (1990) FSH causes a time-dependent stimulation of preovulatory follicle growth in the absence of pulsatile LH secretion in ewes chronically treated with gonadotrophin-releasing hormone agonist Journal of Endocrinology 126 297-307

Price CA and Webb R (1989) Ovarian response to hCG treatment during the oestrous cycle in heifers Journal of Reproduction and Fertility 86 303-308

Price CA, Morris BA and Webb R (1987) Reproductive and endocrine effects of active immunization against a testosterone conjugate in heifers Journal of Reproduction and Fertility 81 149-160

Rajamahendran R and Sianangama PC (1992) Effect of human chorionic gonadotrophin on dominant follicles in cows: formation of accessory corpora lutea, progesterone production and pregnancy rates Journal of Reproduction and Fertility 95 577-584

Ronayne E, Enright WJ and Roche JF (1993) Effects of continuous administration of gonadotropin-releasing hormone $(\mathrm{GnRH})$ or a potent $\mathrm{GnRH}$ analogue on blood luteinizing hormone and testosterone concentrations in prepubertal bulls Domestic Animal Endocrinology 10 179-189

Rusbridge SM (1993) Characterization of the GnRH-induced Corpus Luteum in the Cycling Heifer PhD Thesis, The University of Edinburgh

Savio JD, Thatcher WW, Badinga L, de la Sota RL and Wolfenson D (1993) Regulation of dominant follicle turnover during the oestrous cycle in cows Journal of Reproduction and Fertility 97 197-203

Sawyer HR, Wiepz GJ, Moeller CL, Nett TM and Niswender GD (1991) Failure of hypophysectomized ewes to ovulate in response to gonadotrophins Journal of Reproduction and Fertility Supplement 43 306-307

Scaramuzzi RJ, Adams NR, Baird DT, Campbell BK, Downing JA, Findlay JK, Henderson KM, Martin GB, McNatty KP, McNeilly AS and Tsonis CG (1993) A model for follicle selection and the determination of ovulation rate in the ewe Reproduction Fertility and Development 5 459-478

Turzillo AM and Fortune JE (1990) Suppression of the secondary FSH surge with bovine follicular fluid is associated with delayed ovarian follicular development in heifers Journal of Reproduction and Fertility 89 643-653

Webb R, Gong JG, Law AS and Rusbridge SM (1992) Control of ovarian function in cattle Journal of Reproduction and Fertility Supplement 45 141-156

Webb R, Gong JG and Bramley TA (1994) Role of growth hormone and intrafollicular peptides in the control of follicle development in cattle Theriogenology 41 25-30

Xu Z, Garverick HA, Smith GW, Smith MF, Hamilton SA and Youngquist RS (1995) Expression of follicle-stimulating hormone and luteinizing hormone receptor messenger ribonucleic acids in bovine follicles during the first follicular wave Biology of Reproduction $53951-957$ 